\title{
ADDITIVE REFINEMENTS AND REVERSES OF YOUNG'S OPERATOR INEQUALITY WITH APPLICATIONS
}

\author{
Silvestru SEVEr Dragomir
}

Abstract. In this paper we obtain some new additive refinements and reverses of Young's operator inequality. Applications related to the Hölder-McCarthy inequality for positive operators and for trace class operators on Hilbert spaces are given as well.

Mathematics subject classification (2010): 26D15, 26D10, 47A63, 47A30.

Keywords and phrases: Young's inequality, Hölder-McCarthy operator inequality, arithmetic meangeometric mean inequality.

\section{REFERENCES}

[1] S. S. DRAGOmiR, Some new reverses of Young's operator inequality, Preprint RGMIA Res. Rep. Coll., 18 (2015), Art. 130. [http://rgmia.org/papers/v18/v18a130.pdf] .

[2] S. S. DRAGOMIR, On new refinements and reverses of Young's operator inequality, Preprint RGMIA Res. Rep. Coll., 18 (2015), Art. 135. [http://rgmia.org/papers/v18/v18a135.pdf] .

[3] S. S. DRAGOMIR, Some inequalities for operator weighted geometric mean, Preprint RGMIA Res. Rep. Coll., 18 (2015), Art. 139. [http://rgmia.org/papers/v18/v18a139.pdf ] .

[4] S. S. DRAGOMIR, Refinements and reverses of Hölder-McCarthy operator inequality, Preprint RGMIA Res. Rep. Coll., 18 (2015), Art. 143. [http://rgmia.org/papers/v18/v18a143.pdf] .

[5] S. S. DRAGOMIR, Some reverses and a refinement of Hölder operator inequality, Preprint RGMIA Res. Rep. Coll., 18 (2015), Art. 147. [http://rgmia.org/papers/v18/v18a147.pdf] .

[6] S. Furuichi, Refined Young inequalities with Specht's ratio, J. Egyptian Math. Soc., 20(2012), 4649.

[7] S. FurUichI, On refined Young inequalities and reverse inequalities, J. Math. Inequal., 5 (2011), 21-31.

[8] F. Kittaneh And Y. MANASRAh, Improved Young and Heinz inequalities for matrix, J. Math. Anal. Appl., 361 (2010), 262-269.

[9] F. Kittaneh AND Y. ManasRah, Reverse Young and Heinz inequalities for matrices, Linear Multilinear Algebra, 59 (2011), 1031-1037.

[10] F. Kubo And T. Ando, Means of positive operators, Math. Ann., 264 (1980), 205-224.

[11] W. LiaO, J. Wu AND J. ZhaO, New versions of reverse Young and Heinz mean inequalities with the Kantorovich constant, Taiwanese J. Math., 19 (2015), No. 2, pp. 467-479.

[12] C. A. MCCARThY, $c_{p}$, Israel J. Math., 5 (1967), 249-271.

[13] W. Specht, Zer Theorie der elementaren Mittel, Math. Z., 74 (1960), pp. 91-98.

[14] M. Tominaga, Specht's ratio in the Young inequality, Sci. Math. Japon., 55 (2002), 583-588.

[15] G. Zuo, G. Shi And M. FujII, Refined Young inequality with Kantorovich constant, J. Math. Inequal., 5 (2011), 551-556. 